\title{
Effects of diabetes mellitus on health-related quality of life at a tertiary hospital in South Africa: A cross-sectional study
}

\author{
R Daya, ${ }^{1}$ MB BCh, FCP (SA), MMed; Z Bayat, ${ }^{2}$ MB BCh, FCP (SA); F J Raal, ${ }^{3}$ FRCP, FRCPC, FCP (SA), Cert Endo, MMed, PhD \\ ${ }^{1}$ Department of Endocrinology, Internal Medicine, Chris Hani Baragwanath Academic Hospital, Johannesburg, South Africa \\ ${ }^{2}$ Department of Endocrinology, Internal Medicine, Helen Joseph Hospital, Johannesburg, South Africa \\ ${ }^{3}$ Division of Endocrinology and Metabolism, Department of Medicine, Faculty of Health Sciences, University of the Witwatersrand, \\ Johannesburg, South Africa
}

Corresponding author: R Daya (reyna.daya13@gmail.com)

\begin{abstract}
Background. Diabetes mellitus (DM) is a chronic metabolic disease that potentially causes debilitating and life-threatening complications, demands a lifestyle change, and has important implications with regard to wellbeing and health-related quality of life (HRQOL).

Objectives. To: $(i)$ determine the HRQOL of a sample of patients with type 2 diabetes; (ii) describe the demographics (age, gender, and smoking and alcohol use) of the population studied; (iii) document the following parameters, which are important in determining the control and severity of type 2 diabetes: $(a)$ glycosylated haemoglobin $\left(\mathrm{HbA}_{1 \mathrm{c}}\right),(b)$ total amount of insulin required per day (if on insulin therapy), (c) body mass index (BMI), and (d) exercise compliance; (iv) determine whether there was an association between any or all of the above parameters and the HRQOL of these patients; and $(v)$ determine whether coexisting diseases (hypertension (HT) and dyslipidaemia) were present, and compare HRQOL between diabetic patients with and without these diseases.

Methods. This was a cross-sectional and descriptive study of 200 patients attending the diabetes clinic at Helen Joseph Hospital, Johannesburg, South Africa. HRQOL assessments were made using the Diabetes 39 (D-39) questionnaire, which patients filled in once consent had been obtained and if they fulfilled the inclusion criteria. Patients' questionnaire forms were then analysed with regard to their demographics (age and gender), exercise regimen, smoking and alcohol history, employment status, living arrangements, age of diagnosis of DM, and concurrent use of antihypertensive and cholesterol-lowering drugs. The patients' files were analysed and various clinical parameters were noted $\left(\mathrm{HbA}_{1 \mathrm{c}}\right.$, lipogram, $\mathrm{BMI}$, number of insulin units used per day, and whether any antihypertensive and/or lipidlowering drugs were used).

Results. There was an association between HRQOL and $\mathrm{HbA}_{1 \mathrm{c}}$, and between $\mathrm{HRQOL}$ and $\mathrm{HT}$ and dyslipidaemia.

Conclusions. No association was found between HRQOL and other clinical parameters, namely number of insulin units used per day, exercise, BMI, lipogram and the use of oral hypoglycaemic agents. Demographic parameters (age, gender, age at diagnosis, employment status and living arrangements) were also shown to have no impact on HRQOL. We found no association between HRQOL in patients who consumed alcohol and smoked cigarettes and in those who did not.
\end{abstract}

S Afr Med J 2016;106(9):918-928. DOI:10.7196/SAMJ.2016.v106i9.9899

Quality of life (QOL) is described as a multidimensional construct incorporating an individual's subjective perception of physical, emotional, and social wellbeing, including both a cognitive and an emotional component. ${ }^{[1]}$ Health-related QOL (HRQOL) is increasingly being recognised as an important outcome of health, representing the ultimate goal of all healthcare interventions. ${ }^{[2]}$ Conventional outcome assessment for diabetes mellitus (DM) relies on laboratory indicators, primarily glycosylated haemoglobin $\left(\mathrm{HbA}_{1 \mathrm{c}}\right)$, and complications. ${ }^{[3]}$ However, exclusive reliance on clinical outcomes does not necessarily reflect a patient's perception of his/ her health. Management regimens that require changes in lifestyle and behaviour can influence daily functioning and general wellbeing. HRQOL is therefore increasingly being used as an outcome indicator alongside traditional biomarkers. ${ }^{[3]}$

Guidelines for the treatment of type 2 DM emphasise that one of the primary objectives is to improve HRQOL. ${ }^{[2]}$ Studies show that HRQOL is associated with the duration of diabetes, age, gender, diabetic complications, comorbid diseases and the severity of the disease itself. ${ }^{[2]}$

Patients with diabetes, like those with many other chronic diseases, are less concerned with clinical biomarkers such as $\mathrm{HbA}_{1 \mathrm{c}}$, blood pressure or lipid levels, and more concerned with how the disease will affect their lives in various domains. ${ }^{[4]}$ These domains include physical and social function, emotional and mental health, the burden of the illness and stigma attached to it, and how treatment will impact on their daily life. ${ }^{[4]}$

There is a dearth of South African (SA)-specific information on HRQOL and diabetes. Country-specific HRQOL information may provide improved insight, and potentially lead to improved management of diabetes. The objective of this study was to better understand the effects of diabetes on HRQOL in an SA tertiary-level hospital setting.

\section{Methods}

Ethical approval was received from the Human Research Ethics Committee, University of the Witwatersrand, Johannesburg (protocol no. M120536). This was a clinical audit, cross-sectional in nature, and a descriptive study of consecutive patients attending the diabetes clinic at Helen Joseph Hospital (HJH), a level 3/tertiary state hospital in Johannesburg, over a 3-month period. The study population consisted of 200 patients attending the diabetes clinic at $\mathrm{HJH}$. This sample size was chosen to include all patients who met the inclusion criteria and obtain a fair representation of the population attending the diabetes clinic.

Inclusion criteria. Patients with type $2 \mathrm{DM}$ who had attended the specialist diabetes clinic for $\geq 6$ months. 
Exclusion criteria. Patients with type 1 $\mathrm{DM}$ or blindness, or from whom informed consent could not be obtained.

Fig. 1 shows the study flow.

\section{Measuring HRQOL in diabetes}

Various instruments, generic and disease specific, have been developed to measure HRQOL in diabetes. Generic instruments are designed to investigate aspects of health that are of universal importance, and allow comparisons of HRQOL among different groups of patients. These may be useful for capturing the additional HRQOL deficits associated with comorbid diseases and their respective treatments, such as hypertension (HT), dyslipidaemia and depression, as they incorporate a wider range of dimensions of HRQOL. In contrast, diabetes-specific instruments capture the specific impact that diabetes has on a patient's daily functioning and wellbeing and hence on their QOL, and so could be more sensitive to small clinically important differences. Reviews have shown that the dimensions covered by diabetes-specific instruments vary, but they generally include physical and psychological functioning, fulfilment of the patient's social role, diabetes control and satisfaction with treatment. ${ }^{[2,3]}$

Among the best-known generic instruments are the Short-Form Health Survey (SF-36) (this is the shortened version of the RAND Corporation's MOS Functioning and Well-being profile), the Quality of Well-being (QWB) scale, its successor, the Quality of Well-being Self-Administered Scale (QWB-SA), and the Euroqol 5D and the COOP/WONCA charts. ${ }^{[2,5]}$ The Medical Outcomes Study 36-Item Short-Form Health Survey (SF-36) is a commonly used generic instrument for diabetes, while the Diabetes-39 (D-39) questionnaire has been demonstrated to have good psychometric properties. $^{[2]}$

\section{The D-39 questionnaire}

The D-39 questionnaire ${ }^{[5]}$ (Appendix 1) was used in this study. Developed by Boyer and Earp, this is a 39 -item instrument that was designed to assess HRQOL in patients with type 1 and type $2 \mathrm{DM}$. The developers did not give express consideration to face/content validity, but used extensive literature reviews, existing QOL questionnaires and interviews with health professionals and patients with diabetes. ${ }^{[5]}$ Written permission to use the D-39 questionnaire was obtained from them.

The D-39 questionnaire encompasses measurements of energy and mobility, diabetes control, anxiety and worry, social burden and sexual functioning. Patients are asked how much the quality of their life was affected by

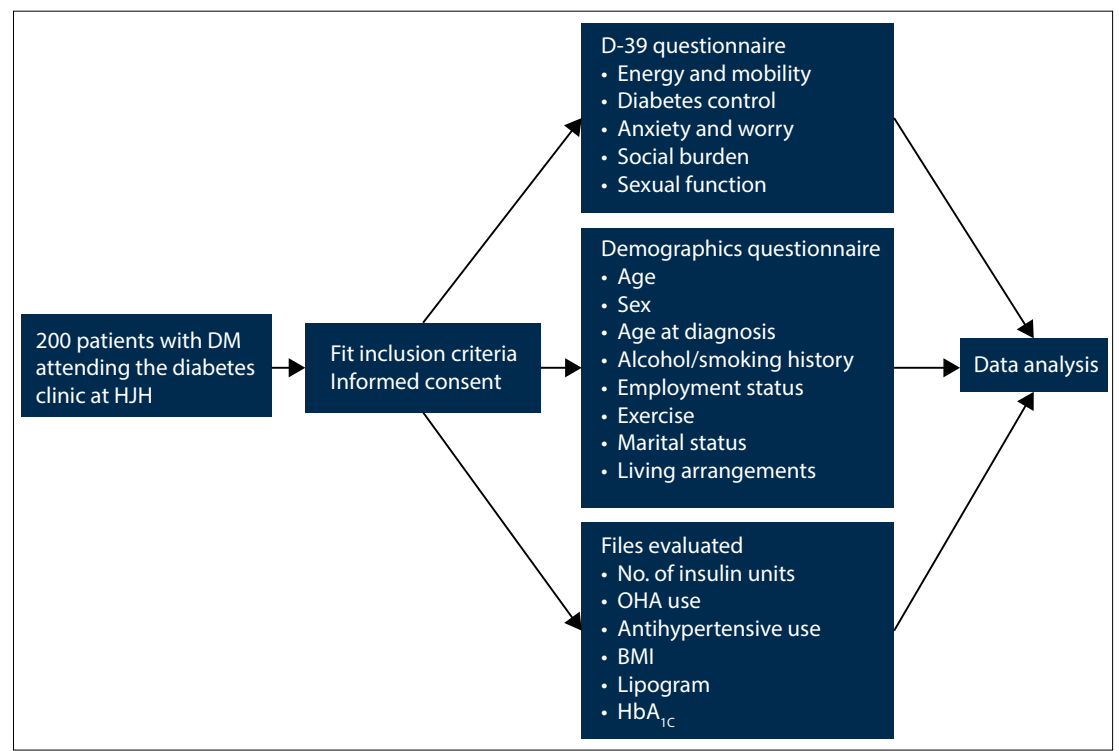

Fig. 1. The study flow.

a wide range of aspects of diabetes illness and its treatment in the past month. Items are administered using seven response categories, ranging from not affected at all (score $=1$ ) to extremely affected (score $=7$ ). The detailed D-39 scoring instructions and further information in this regard are available from the author (reyna.daya13@gmail.com). The reliability of the questionnaire is acceptable, with a Cronbach alpha of $0.81-0.93$ for all the subscales. The construct validity has been compared with the widely used SF-36 and found to be very satisfactory.

The D-39 questionnaire has been recommended for use in research and clinical settings. The instrument provides evidence for validity and reliability, includes several domains that cover various aspects of QOL, and is therefore applicable to a wide population of patients. ${ }^{[5]}$ It is one of few diabetes-specific QOL measures that have been shown to be responsive to changes in health status. ${ }^{[5,6]}$ Importantly, it does not impose a definition of QOL upon patients, but instead allows them to respond in the context of their personal conceptualisation of QOL. ${ }^{[5]}$ These attributes make the instrument highly patient-centered, one of the most critical components of any patientassessed QOL measure. ${ }^{[5,6]}$

The following measurements of the severity and control of diabetes were used in this study:

- Demographics (age, gender)

- Smoking pack-year history (number of cigarettes smoked per day divided by pack of 20 cigarettes multiplied by number of years smoked). Factors such as brand and strength (nicotine and tar content) were not measured.
- Alcohol units consumed per week. The study did not distinguish between types of alcohol consumed (wine, spirits, etc.).

- Number of insulin units used per day. The study did not distinguish between the types of insulin used (i.e. rapid- or longacting insulin) or the number of times a patient injected him/herself (daily or twice-daily regimens).

- Use of antihypertensive or lipid-lowering medication or oral hypoglycaemic agents (OHAs)

- Exercise. Patients were considered to be exercising if they attended a gym/ sporting/recreational facility at least three times a week or if they reported doing an exercise routine by themselves for at least 30 minutes, three times a week. This routine must have been followed for at least 1 month. The study did not distinguish between the grades of physical activity.

- Weight was measured using a standard calibrated scale placed on the floor. Patients were weighed while standing barefoot and were instructed not to hold onto any form of support.

- Height was measured with a tape measure and recorded to the nearest centimetre. The patient was requested to stand barefoot with his/her heels together and touching the wall, with his/her back against a wall.

- Body mass index (BMI) was calculated using Quetelet's formula (weight (kg)/ height $^{2}$ ) and defined using the World Health Organization (WHO) classification (underweight $<20 \mathrm{~kg} / \mathrm{m}^{2}$ ), normal 20 $24.9 \mathrm{~kg} / \mathrm{m}^{2}$, overweight $>25-29.9 \mathrm{~kg} / \mathrm{m}^{2}$, and obese $>30 \mathrm{~kg} / \mathrm{m}^{2}$ ). 
- Most recent lipid profile

- Latest $\mathrm{HbA}_{\mathrm{lc}}$ level.

\section{Statistical analysis}

All data collected were extrapolated onto an Excel 2010 spreadsheet (Microsoft, USA), and STATISTICA 12 (StatSoft, USA) was used for descriptive statistics (means, medians, modes, standard deviations (SDs) and interquartile ranges (IQRs), where appropriate). In addition to the descriptive statistics, a principal component analysis (PCA) was performed. The PCA allowed for reduction in the number of variables for analysis and subsequently for the variables explaining the largest amount of variance to be analysed in the context of the objectives of the study.

Data were checked for normality (normal distribution), but normality is often not achieved in social studies. In order to mitigate against this, data were bootstrapped 100000 times to ensure that sufficient variance existed in the data and that the results obtained could be interpreted confidently.

To assess whether there were factors influencing QOL, associations between variables were analysed using Pearson's correlation coefficient. It is important to note that the associations should not to be interpreted as causal factors.

Continuous data were presented as median values with IQRs, and categorical data were described using proportions. Student's $t$-test for unpaired data was performed to compare medians between groups when the data were normally distributed, and the Mann-Whitney test was used when the data were not normally distributed. Fisher's exact test was used to compare categorical variables between groups. A $p$-value of $<0.05$ was considered significant.

\section{Results}

Data were collected from 220 patients. Twenty patients were excluded from the study owing to an incompletely filled-in questionnaire $(n=14)$ or lack of data recorded in the file $(n=6)$. Ten patients were approached but refused to participate in the study. Table 1 shows the demographic profile of the patients analysed.

\section{Diabetes control}

Khanna et al. ${ }^{[7]}$ report that on a transformed scale of 0 - 100, a score closer to 0 indicates a better QOL and a score closer to 100 a worse QOL. The mean score for diabetes control in our study was 43.65 .

\section{Anxiety and worry}

The mean score for anxiety and worry in our study was 53.77 (mean for males 51.58, mean for females 55.42). Nineteen patients had a score of 71.43 (the mode, or most frequently observed score) (range $7.14-235.71)$

\section{Social burden}

Possible scores for social burden ranged from 7.14 to 92.86 . The mean score in our study was 32.76 (mean for males 30.66 , mean for females 34.34). The mode was 7.14, with 22 patients having this score.

\section{Sexual function}

The total mean score in our study was 51.76 (mean for females 45.66, mean for males 59.86). The mode was 7.14, with 35 patients having this score (range 2.38 - 92.86).

\section{Energy and mobility}

The total mean score in our study was 43.65 (mean for females was 46.66 and for males 39.63). The mode was 36.90 , with 12 patients having this score (range 7.14 - 92.86).

\section{Overall ratings}

The five aspects of QOL in the D-39 questionnaire all affect HRQOL and are set out in Table 2 .

Table 1. Demographic and cohort characteristics of the study subjects

\begin{tabular}{ll}
\hline Parameter & Results \\
\hline Total patients, $N$ & 200 \\
Gender, $n(\%)$ & \\
$\quad$ Males & $86(43.0)$ \\
$\quad$ Females & $114(57.0)$
\end{tabular}

Age (yr)

Mean (SD), median (range)

$55.89(12.52)$ $58(30-82)$

Males, mean (SD)

$53.29(12.73)$

Females, mean (SD) $57.85(12.04)$

Age distribution (years), $n$ (\%)

$30-40$

$41-50$

$51-60$

$\geq 61$

Age at diagnosis (years)

Mean (SD), median (range)

$42.19(10.74)$ $40(18-72)$

Males, mean (SD)

Females, mean (SD)

Employment status, $n$ (\%)

Employed

Unemployed

Living arrangements, $n$ (\%)

Live alone

Live with others

$174(87.0)$

Cigarette smoking, $n$ (\%)

Cigarette use (pack-years)

$0.1-10$

$10.1-20$

$20.1-40$

$>40.1$

No cigarette use

Alcohol consumption, $n$ (\%)

Consume alcohol

1 - 5 units per week

5.1 - 10 units per week

No alcohol consumed

OHAs with insulin use, $n(\%)$

Metformin

Sulphonylurea

Exercise, $n$ (\%)

Regular exercise

$106(53.0)$

No exercise

$94(47.0)$

Continued .. 
Table 1. (continued) Demographic and cohort characteristics of the study subjects

\begin{tabular}{|c|c|}
\hline Parameter & Results \\
\hline \multicolumn{2}{|c|}{$\begin{array}{l}\text { Insulin used/not used, and no. of units used per day, } \\
n(\%)\end{array}$} \\
\hline Insulin used & $199(99.5)$ \\
\hline $0.1-40$ & $63(31.7)$ \\
\hline $40.1-80$ & $89(44.7)$ \\
\hline $80.1-120$ & $25(12.6)$ \\
\hline $120.1-160$ & $3(1.5)$ \\
\hline $160.1-20$ & $4(2.0)$ \\
\hline No insulin use & $1(0.5)$ \\
\hline \multicolumn{2}{|c|}{ Coexisting diseases, $n(\%)$} \\
\hline HT & $148(74.0)$ \\
\hline Dyslipidaemia & $140(70.0)$ \\
\hline $\mathrm{HT}+$ dyslipidaemia & $128(64.0)$ \\
\hline \multicolumn{2}{|l|}{$\mathrm{HbA}_{1 \mathrm{c}}(\%), n(\%)$} \\
\hline$\leq 7$ & $28(14.0)$ \\
\hline $7.1-7.9$ & $28(14.0)$ \\
\hline $8-8.9$ & $23(11.5)$ \\
\hline $9-9.9$ & $41(20.5)$ \\
\hline$\geq 10$ & $80(40.0)$ \\
\hline \multicolumn{2}{|c|}{ Total cholesterol (mmol/L), $n(\%)$} \\
\hline$\leq 4.5$ (target level) & $113(56.5)$ \\
\hline $4.6-4.9$ & $22(11.0)$ \\
\hline $5.0-6.0$ & $42(21.0)$ \\
\hline $6.1-7.0$ & $15(7.5)$ \\
\hline$\geq 7.1$ & $8(4.0)$ \\
\hline
\end{tabular}

Triglyceride (mmol/L), $n(\%)$

$\leq 1.7$ (target level)

$123(61.5)$

$1.8-2.5$

38 (19.0)

$2.6-3.5$

$23(11.5)$

$3.6-4.5$

$11(5.5)$

$\geq 4.6$

HDL (mmol/L), $n(\%)$

$\leq 1.2$ (target level)

$128(64.0)$

$1.3-2.0$

$60(30.0)$

$2.1-3.0$

$8(4.0)$

$3.1-4.0$

$1(0.5)$

$\geq 4.1$

LDL (mmol/L), $n(\%)$

$\leq 1.8$ (target level)

$1.9-2.5$

65 (32.5)

$2.6-3.5$

$54(27.0)$

$3.6-4.5$

$19(9.5)$

$\geq 4.6$

$9(4.5)$

$5(2.5)$

Blank
Table 1. (continued) Demographic and cohort characteristics of the study subjects

\begin{tabular}{ll}
\hline Parameter & Results \\
\hline BMI, $n(\%)$ & \\
$\quad$ Underweight $\left(<20 \mathrm{~kg} / \mathrm{m}^{2}\right)$ & $5(2.5)$ \\
Normal $\left(20-24.9 \mathrm{~kg} / \mathrm{m}^{2}\right)$ & $31(15.5)$ \\
Overweight $\left(>25-29.9 \mathrm{~kg} / \mathrm{m}^{2}\right)$ & $41(20.5)$ \\
$\quad$ Obese $\left(>30 \mathrm{~kg} / \mathrm{m}^{2}\right)$ & $123(61.5)^{*}$ \\
$\begin{array}{l}\text { *OD }=\text { high-density lipoprotein; } \mathrm{LDL}=\text { low-density lipoprotein. } \\
\text { ( } 6.2 \%(n=74) \text { were female and } 39.8 \%(n=49) \text { male. }\end{array}$ &
\end{tabular}

While Table 2 indicates the HRQOL factors, further examination of the factors that individuals perceive as influencing QOL was done using a PCA (Table 3). The results show that sexual function, anxiety and worry and diabetes control are the main factors that influence HRQOL. PCA 1, representing the psychological component of HRQOL, was most influenced by sexual function, anxiety and worry, and social burden, while PCA 2, representing the physical effects of the diabetes, was influenced by diabetes control, and energy and mobility. Table 3 indicates that sexual function accounts for the most variation in the dataset of all the constructs that measure QOL. Significant associations between HRQOL and the parameters investigated are set out in Table 4.

\section{Discussion}

Our results indicate that a greater number of females than males responded to the questionnaire. While this does not mean that females are more susceptible to DM, respondent bias may be a possible explanation for the greater number of female respondents ( $n=114$ v. 86). While the gender distribution may reflect the male/ female ratio of patients attending the diabetes clinic, analysing demographics was not the objective of the study, although it may prove to be a fruitful area for further research focusing specifically on gender. With this in mind, we did note interesting gender differences that may support earlier research conducted by authors such as Rubin and Peyrot, ${ }^{[1]}$ who reported that HRQOL is better among diabetic men than among diabetic women.

We found a mean HRQOL score of 216.98 for males and 223.78 for females. These scores indicate that females with DM may have a reduced QOL compared with males. Rubin and Peyrot ${ }^{[1]}$ reported that males are more satisfied with their diabetes treatment regimen than women, and missed fewer days of work and fewer leisure activities as a result of DM. Furthermore, it has been reported that men with diabetes report less disease impact and greater treatment satisfaction than women. ${ }^{[8]}$ These results are consistent with a study conducted in the Netherlands, which found that women with DM had significantly lower HRQOL scores than men. ${ }^{[9]}$ The differences were explained as being due to gender differences in levels of obesity. The present study supports these results, as females were found to be more obese than males, and therefore supports the view that obesity may affect HRQOL and have an adverse impact on females.

There have been differing reports on age as a factor affecting diabetic patients' QOL. Brown et al. ${ }^{[10]}$ and Rubin and Peyrot ${ }^{[1]}$ reported that age has no effect on QOL, but Redekop et al. ${ }^{[9]}$ reported that it may have a negative effect. They attributed this to older people having lower levels of energy, physical activity and social functioning. Our results, however, indicated that there is no association between age and HRQOL. This finding is consistent with those of Brown et $a l .{ }^{[10]}$ and Rubin and Peyrot. ${ }^{[1]}$ While we could not find an explanation 
Table 2. Linear transformed ratings

\begin{tabular}{llllll}
\hline & $\begin{array}{l}\text { Diabetes } \\
\text { control }\end{array}$ & $\begin{array}{l}\text { Anxiety } \\
\text { and worry }\end{array}$ & $\begin{array}{l}\text { Social } \\
\text { burden }\end{array}$ & $\begin{array}{l}\text { Sexual } \\
\text { function }\end{array}$ & $\begin{array}{l}\text { Energy } \\
\text { and } \\
\text { mobility }\end{array}$ \\
\hline Mean total & 43.65 & 53.77 & 32.76 & 51.76 & 38.91 \\
Mean male & 39.63 & 51.58 & 30.66 & 59.86 & 35.2 \\
Mean female & 46.66 & 55.42 & 34.34 & 45.66 & 41.71
\end{tabular}

Table 3. Principal component analysis

\begin{tabular}{lll}
\hline & PCA 1 & PCA 2 \\
\hline Sexual function & 0.71 & -0.69 \\
Anxiety and worry & 0.53 & 0.47 \\
Social burden & 0.30 & 0.29 \\
Diabetes control & 0.27 & 0.38 \\
Energy and mobility & 0.19 & 0.24
\end{tabular}

Table 4. Significant associations $(p<0.05$ and $p<0.01)$ between HRQOL and the parameters investigated

\begin{tabular}{|c|c|c|c|c|c|c|c|c|c|}
\hline & HRQOL & High BP & $\begin{array}{l}\text { High } \\
\text { cholesterol }\end{array}$ & $\begin{array}{l}\text { Diabetes } \\
\text { control }\end{array}$ & $\begin{array}{l}\text { Anxiety/ } \\
\text { worry }\end{array}$ & $\begin{array}{l}\text { Social } \\
\text { burden }\end{array}$ & $\begin{array}{l}\text { Sexual } \\
\text { function }\end{array}$ & $\begin{array}{l}\text { Energy/ } \\
\text { mobility }\end{array}$ & $\mathbf{H B A}_{1 \mathrm{C}}$ \\
\hline HRQOL & 1 & & & & & & & & \\
\hline High BP & $-0.232^{* *}$ & 1 & & & & & & & \\
\hline High cholesterol & $-0.301^{* *}$ & $0.607^{* *}$ & 1 & & & & & & \\
\hline Diabetes control & $0.745^{* *}$ & $-0.174^{*}$ & $-0.306^{* *}$ & 1 & & & & & \\
\hline Anxiety/worry & $0.781^{* *}$ & -0.064 & $-0.171^{*}$ & $0.603^{* *}$ & 1 & & & & \\
\hline Social burden & $0.728^{* *}$ & -0.076 & $-0.191^{* *}$ & $0.573^{* *}$ & $0.469^{* *}$ & 1 & & & \\
\hline Sexual function & $0.667^{* *}$ & $-0.187^{* *}$ & $-0.167^{*}$ & $0.186^{* *}$ & $0.344^{* *}$ & $0.270^{* *}$ & 1 & & \\
\hline Energy/mobility & $0.606^{* *}$ & $-0.362^{* *}$ & $-0.294^{* *}$ & $0.532^{* *}$ & $0.296^{* *}$ & $0.464^{* *}$ & $0.167^{*}$ & 1 & \\
\hline $\mathrm{HBA}_{\mathrm{lc}}$ & $-0.155^{*}$ & 0.069 & 0.041 & $-0.166^{*}$ & -0.045 & $-0.214^{* *}$ & -0.082 & -0.086 & 1 \\
\hline
\end{tabular}

for this in the literature, it may indicate that while physical health does decline with age, older people are not necessarily physically incapacitated and unenergetic.

The literature also reports conflicting findings on the relationship between duration of DM and HRQOL. The duration of DM has been reported to be associated with a decreased HRQOL. ${ }^{[1]}$ A possible reason for this could be that the longer a patient has DM, the more complications may develop, thus worsening QOL. Rubin and Peyrot ${ }^{[1]}$ and Redekop et al. ${ }^{[9]}$ found no association between duration of DM and HRQOL, which is supported by the present study. No explanation for this could be found in the literature. A possible reason could be that the duration of DM does not necessarily correlate with good control, experience with treatment or level of complications, so not necessarily impacting on QOL.

The never-ending demands on the patient with diabetes, such as watching one's diet, exercising regularly, monitoring blood glucose levels, and scheduling and planning life around one's treatment, affects QOL in patients with both type 1 and type $2 \mathrm{DM}^{\left[{ }^{[1]}\right.}$ It could be assumed that in addition to improving glucose control and reducing diabetes-related complications, improved adherence to a treatment regimen would lead to improved HRQOL, but some studies indicate that engaging in selfmanagement behaviour has a negative effect on QOL. ${ }^{[12,13]}$ Watkins et $a l .{ }^{[13]}$ have suggested that dietary adherence may negatively affect QOL by increasing the level of perceived diabetes-related burden. People affected by DM are often restricted with regard to the amount, type and timing of food consumed (e.g. having to be aware of the glycaemic index of foods, eating mandatory meals at certain times, waiting for insulin to take effect before eating meals, etc.). These restrictions may negatively affect an individuals QOL and their interaction with people around them, in their social lives and in the workplace. ${ }^{[13]}$

The present study found an association between a diabetic patient's HRQOL and diabetes control as measured by $\mathrm{HbA}_{1 c}$. The reasons are probably multifactorial, ranging from dietary restrictions to being deterred from engaging in social events and the time and commitment required to achieve good glycaemic and weight control.

Connel et al. ${ }^{[11]}$ reported an association between socioeconomic status (income and level of education) and HRQOL. We used employment to indicate socioeconomic status, but found no association. This may be because employment is not a reliable means of assessing an individual's socioeconomic status (e.g. employment status does not necessarily reflect financial status), so employment status may not have a significant impact on HRQOL. The fact that unemployment rates in SA are extremely high should also be kept in mind.

Exercise is closely related to weight control, which is reported to be an important factor in the management of diabetes. However, our results indicate that only half of the study population reported exercising regularly. This may be related to age (median 58 years), with older age being associated with a progressively more sedentary lifestyle, worsening the problem of DM and general HRQOL. Furthermore, physical strength decreases as an individual ages, and this may also be compounded by diabetes-related complications. Patients often do not perceive exercise as having a potential positive impact on QOL, which is further evidenced by the lack of an association between HRQOL and exercise.

Fal et al.$^{[14]}$ reported that BMI affects QOL. However, results from the present study provide no evidence for an association between the two, and indicate that while BMI and therefore weight may be significant in some specific medical conditions, they have no impact on DM. While being overweight may be linked to QOL, patients do not perceive it to be significant with specific reference to DM.

DM and HT appear to comparably impair HRQOL. ${ }^{[15]}$ We found an association between HRQOL and concomitant $\mathrm{HT}$ and dyslipidaemia. DM and HT have comparable adverse effects on HRQOL. ${ }^{[15]}$ 
According to the American Diabetes Association, sexual dysfunction is one of the most common complications of DM and also one of the most underdiagnosed. Diabetic men are three times as likely as non-diabetic men to develop erectile dysfunction (ED). The cause is often multifactorial, but most commonly reflects endothelial dysfunction and autonomic neuropathy. ${ }^{[16]}$ Studies have shown that sexual dysfunction, ED in particular, negatively affects QOL. The Exploratory Comprehensive Evaluation of Erectile Dysfunction study reported that among patients in the general population presenting to a urologist, ED negatively affected both general QOL and HRQOL. ${ }^{[16]}$

According to the Canadian Diabetes Association, little is known about the relationship between DM and anxiety. ${ }^{[17]}$ The prevalence of anxiety disorders seems to higher in patients with diabetes (14\%) than in the general population ( $3-4 \%)$. As many as $40 \%$ of diabetic patients have at least some anxiety symptoms. ${ }^{[17]}$ Fear of hypoglycaemia is common in patients with DM, and while it may not affect HRQOL per se (e.g. it has little impact on pain or mobility), it can affect aspects of more general QOL (e.g. independence, ability to work or perform household duties, enjoyment of leisure activities). Sheu et al. ${ }^{[18]}$ found that hypoglycaemic symptoms were associated with reduced QOL, as well as increased anxiety and worry, in diabetic patients treated with OHAs. ${ }^{[18]}$ The present study found an association between anxiety and worry and HRQOL in patients with type 2 diabetes, whether they were treated with insulin alone or with OHAs.

The effects of lifestyle interventions in type $2 \mathrm{DM}$ are relatively well described in the literature. ${ }^{[6,19,20]}$ It has been noted that many such strategies can reduce the complications of type 2 DM. Lifestyle modification in relation to loss of weight, changing eating habits, cessation of cigarette smoking, reducing alcohol consumption and increasing physical exercise can play a major role in preventing complications related to DM. Although there has been substantial work on developing behavioural strategies to aid these lifestyle modifications, they are not easy to implement or to maintain on a long-term basis. Our study found no association between HRQOL and whether individuals drank alcohol and smoked cigarettes or not. However, although religious belief was not included in the questionnaire, our respondents included a substantial number of Muslims, who do not drink alcohol for religious reasons.

Clinicians need to keep a wide range of factors in mind when creating a treatment regimen for patients with DM. It is important to consider how DM affects each patient's QOL, but resource constraints in the public sector make it a challenge to solve these problems. Psychological factors such as mental and physical strain need to be considered, together with costs associated with healthcare visits, days spent away from work, and loss of independence. Managing DM holistically by attempting to improve the psychological aspect of the patient's disease as well as controlling blood glucose levels, blood pressure and cholesterol levels may lead to better HRQOL.

\section{Study limitations}

Global inferences are limited by the study design, duration and sample size and the fact that the study cohort represented a small group of patients, with poorly controlled blood glucose levels. Another limitation is that it was a non-random sample, conducted at a specialist diabetic clinic.

\section{Conclusions}

The results show an association between $\mathrm{HbA}_{1 c}$ and HRQOL. Furthermore, there was an association between HRQOL and HT and dyslipidaemia. No association was found between HRQOL and other clinical parameters, namely number of insulin units used per day, exercise, BMI, lipogram and the use of OHAs. Demographic parameters (age, gender, age at diagnosis, employment status and living arrangements) were also shown to have no impact on HRQOL in this study. Whether an individual consumed alcohol or smoked cigarettes did not affect his/her HRQOL.

1. Maddigan S, Majumdar S, Toth E, Feeny D, Johnson J, DOVE Investigators. Health-related quality of life deficits associated with varying degrees of disease severity in type 2 diabetes. Health Qual Life Outcomes 2003;1(1):78. DOI: 10.1186/1477-7525-1-78

2. Huang IC, Hwang C-C, Wu M-Y, Lin W, Leite W, Wu AW. Diabetes-specific or generic measures for health-related quality of life? Evidence from psychometric validation of the D-39 and SF-36. Value Health 2008;11(3):450-461. DOI:10.1111/j.1524-4733.2007.00261.x

3. Rozenbaum EA, Chaimovitz C, Bearman JE. Quality of life of patients on chronic dialysis. Isr J Med Sci 1984;20(2):104-108

Boyer JG, Earp JAL. The development of an instrument for assessing the quality of life of people with diabetes: Diabetes-39. Med Care 1997;35(5):440-453.

Watkins $\mathrm{K}$ Connell $\mathrm{CM}$. Measurement of health-related QOL in diabetes mellitus, Pharmacoeconomics 2004;22(17):1109-1126.

6. Khanna A, Bush AL, Swint JM, Peskin MF, Street RL Jr, Naik AD. Hemoglobin A improvements and better diabetes-specific quality of life among participants completing diabetes self-management programs: A nested cohort study. Health Qual Life Outcomes 2012;10:48. DOI:10.1186/1477-7525$0-48$

7. Wredling R, Stalhammar J, Adamson U, Berne C, Larsson Y, Oestman J. Well-being and treatment satisfaction in adults with diabetes: A Swedish population-based study. Qual Life Res 1995;4(6):515522.

8. Redekop WK, Koopmanschap MA, Stolk RP, Rutten GEHM, Wolffenbuttel BHR, Niessen LW. Healthrelated quality of life and treatment satisfaction in Dutch patients with type 2 diabetes. Diabetes Care 2002;25(3):458-463. DOI:10.2337/diacare.25.3.458

9. Brown GC, Brown MM, Sharma S, Brown H, Gozum M, Denton P. Quality of life associated with diabetes mellitus in an adult population. J Diabetes Complications 2000;14(1):18-24. DOI:10.1016/ S1056-8727(00)00061-1

10. Connel CM, Dawis WK, Gallant MP, Sharpe PA. Impact of social support, social cognitive variables, and perceived threat on depression among adults with diabetes. Health Psychol 1994;13(3):263-273. DOI:10.1037/0278-6133.13.3.263

11. Glasgow RE, Ruggiero L, Eakin EG, Dryfoos J, Chobanian L. Quality of life and associated characteristics in a large national sample of adults with diabetes. Diabetes Care 1997;20(4):562-567. DOI-102337/diacare 20.4.562

12. Watkins KW, Connell CM, Fitzgerald JT, et al. Effect of adults' self-regulation of diabetes on quality-oflife outcomes. Diabetes Care 2000;23(10):1511-1515. DOI:10.2337/diacare.23.10.1511

13. Fal AM, Jankowska B, Uchmanowicz I, Sen M, Panaszek B, Polanski J. Type 2 diabetes quality of life patients treated with insulin and oral hypoglycemic medication. Acta Diabetol 2011;48(3):237-242. DOI: 10.1007/s00592-010-0244-y

14. Lloyd A, Sawyer W, Hopkinson P. Impact of long-term complications on quality of life in patients with type 2 diabetes not using insulin. Value Health 2001;4(5):392-400. DOI:10.1046/j.15244733.2001.45029.x

15. Latini DM, Penson DF, Lubeck DP, Wallace KL, Henning JM, Lue TF. Longitudinal differences in disease specific quality of life in men with erectile dysfunction: Results from the Exploratory Compene DOI:10.1097/01

16. Canadian Diabetes Association. Diabetes and you. http://www.diabetes.ca/diabetes-and-you/living/ complications/depression/ (accessed 18 February 2014).

17. Sheu WH, Ji LN, Nitiyanant W, Baik SH, Yin D, Mavros P, Chan SP. Hypoglycemia is associated with increased worry and lower quality of life among patients with type 2 diabetes treated with oral antihyperglycemic agents in the Asia-Pacific region. Diabetes Res Clin Pract 2012;96(2):141-148. DOI:10.1016/j.diabres.2011.12.02

18. Deakin TA, Cade JE, Williams RDC, Greenwood DC. Structured patient education: The Diabetes X-PERT Programme makes a difference. Diabet Med 2006;23(9):944-954. DOI:10.1111 /j.1464-5491.2006.01906

19. Duke AS, Colagiuri S, Colagiuri R. Individual patient education for people with type 2 diabetes mellitus. Cochrane Database Syst Rev 2009, Issue 1. Art. No.: CD005268. DOI:10.1002/14651858. CD005268.pub2

Accepted 28 June 2016. 


\section{Appendix 1. The D-39 questionnaire}

\section{Quality of Life Survey}

A person's quality of life is affected by many things. These things might include health, the opportunity for recreation and vacations, friends and family, and a job. This questionnaire is designed to help us learn about what affects the quality of life of people with diabetes.

Below are questions about your quality of life. For each factor listed, we ask you to place an " $X$ " on the line to show whether that factor affects your quality of life "extremely," "not at all," or some place in the middle. An example is shown in the box below. For example, if you thought "having an automobile" affected your quality of life to some extent, but not extremely, you might mark the line as shown.

\section{DURING THE PAST MONTH, HOW MUCH WAS THE QUALITY OF YOUR LIFE AFFECTED BY:} having an automobile

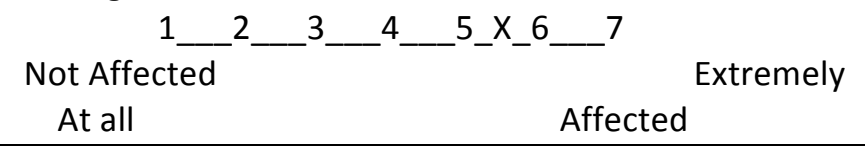

DURING THE PAST MONTH, HOW MUCH WAS THE QUALITY OF YOUR LIFE AFFECTED BY:

1. Your diabetes medication schedule

$\begin{aligned} & \text { Not Affected } \\ & \text { At all }\end{aligned}$
${ }^{2}-3-4-5-6$
$\begin{aligned} & \text { Extremely } \\ & \text { Affected }\end{aligned}$

2. Worries about money matters

$\begin{aligned} & \text { Not Affected } \\ & \text { At all }\end{aligned}$
${ }^{2}-3-4-5-6-6$
$\begin{aligned} & \text { Extremely } \\ & \text { Affected }\end{aligned}$

3. Limited energy levels

\begin{tabular}{|c|c|}
\hline Not Affected & Extremely \\
\hline
\end{tabular}

4. Following your doctor's prescribed treatment plan for diabetes

$\begin{aligned} & \text { Not Affected } \\ & \text { At all }\end{aligned}$
$\begin{aligned} & 1,3-4-5-6 \\ & \text { Affected }\end{aligned}$

5. Food restrictions required to control your diabetes

$\begin{aligned} & \text { Not Affected } \\ & \text { At all }\end{aligned}$
$1^{2}-3-4-5-6$
$\begin{aligned} & \text { Extremely } \\ & \text { Affected }\end{aligned}$

6. Concerns about your future

$\begin{aligned} & \text { Not Affected } \\ & \text { At all }\end{aligned}$
$\begin{aligned} & 1{ }^{2}-3-4-5 \\ & \text { Affected }\end{aligned}$


7. Other health problems besides diabetes

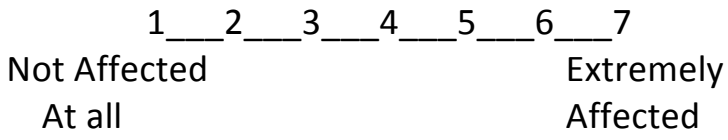

8. Stress or pressure in your life

$\begin{aligned} & \text { Not Affected } \\ & \text { At all }\end{aligned}$
${ }^{1}-{ }^{2}-4-5-6$
$\begin{aligned} & \text { Extremely } \\ & \text { Affected }\end{aligned}$

9. Feelings of weakness

$\begin{aligned} & \text { Not Affected } \\ & \text { At all }\end{aligned}$
${ }^{1}-{ }^{3}-{ }^{4}-5-6$
Affected

10. Restrictions on how far you can walk

$\begin{aligned} & \text { Not Affected } \\ & \text { At all }\end{aligned}$
${ }^{1}-{ }^{2}-4-5-6$
$\begin{aligned} & \text { Extremely } \\ & \text { Affected }\end{aligned}$

11. Exercise requirements

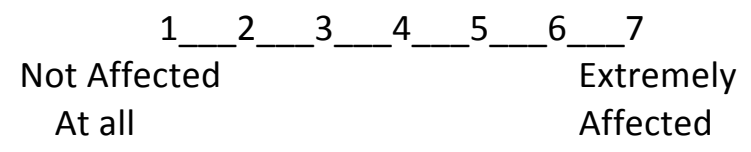

12. Loss or blurring of your vision

$\substack{\text { Not Affected } \\ \text { At all }}$
$1^{2}-3-4-5-6$
$\begin{aligned} & \text { Extremely } \\ & \text { Affected }\end{aligned}$

13. Not being able to do what you want

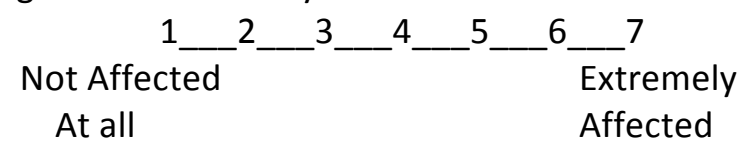

14. Having diabetes

$\begin{gathered}\text { Not Affected } \\ \text { At all }\end{gathered}$
${ }_{\text {Affected }}$

15. Losing control of your sugar levels

\begin{tabular}{|c|c|}
\hline Not Affected & ${ }^{6}{ }^{7}$ \\
\hline At all & Affected \\
\hline
\end{tabular}

16. Other illnesses besides diabetes

$\begin{aligned} & \text { Not Affected } \\ & \text { At all }\end{aligned}$
${ }^{1}-3-4-5-6$
$\begin{aligned} & \text { Extremely } \\ & \text { Affected }\end{aligned}$


17. Testing your sugar (glucose) levels

$\begin{aligned} & \text { Not Affected } \\ & \text { At all }\end{aligned}$
$\begin{aligned} & \text { Extremely } \\ & \text { Affected }\end{aligned}$

18. The time required to control your diabetes

$\begin{aligned} & \text { Not Affected } \\ & \text { At all }\end{aligned}$
$\begin{aligned} & 1 \\ & \text { Affected }\end{aligned}$

19. The restrictions your diabetes places on your family and friends

$\begin{gathered}\text { Not Affected } \\ \text { At all }\end{gathered}$
$\begin{aligned} & 1 \\ & \text { Affected }\end{aligned}$

20. Being embarrassed because you have diabetes

$\begin{aligned} & \text { Not Affected } \\ & \text { At all }\end{aligned}$
$\begin{aligned} & \text { Extremely } \\ & \text { Affected }\end{aligned}$

21. Diabetes interfering with your sex life

$\begin{aligned} & \text { Not Affected } \\ & \text { At all }\end{aligned}$
$\begin{aligned} & \text { Extremely } \\ & \text { Affected }\end{aligned}$

22. Feeling blue or depressed

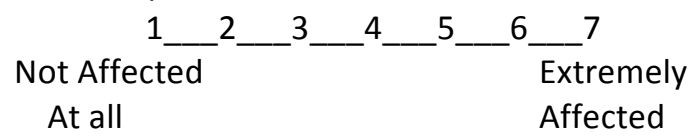

23. Problems with sexual functioning

$\begin{aligned} & \text { Not Affected } \\ & \text { At all }\end{aligned}$
$\begin{aligned} & \text { Extremely } \\ & \text { Affected }\end{aligned}$

24. Getting your diabetes well controlled

$\begin{aligned} & \text { Not Affected } \\ & \text { At all }\end{aligned}$
$\begin{aligned} & \text { Extremely } \\ & \text { Affected }\end{aligned}$

25. Complications from your diabetes

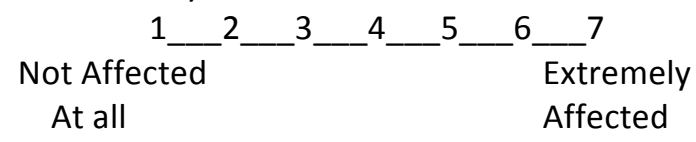

26. Doing things that your family or friends don't do

$\begin{aligned} & \text { Not Affected } \\ & \text { At all }\end{aligned}$
$\begin{aligned} & \text { Extremely } \\ & \text { Affected }\end{aligned}$


27. Keeping a record of your sugar levels

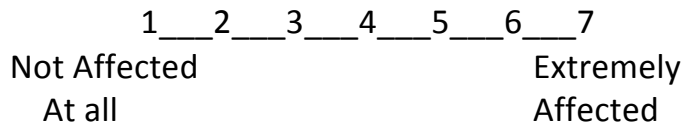

28. The need to eat at regular intervals

$\begin{aligned} & \text { Not Affected } \\ & \text { At all }\end{aligned}$
$\begin{aligned} & 1{ }^{2}-3-4-5-6 \\ & \text { Affected }\end{aligned}$

29. Not being able to do housework or other jobs around the house

$\begin{aligned} & \text { Not Affected } \\ & \text { At all }\end{aligned}$
$\begin{aligned} & 1+3+5-6 \\ & \text { Affected }\end{aligned}$

30. A decreased interest in sex

$\begin{aligned} & \text { Not Affected } \\ & \text { At all }\end{aligned}$
$\begin{aligned} & \text { Extremely } \\ & \text { Affected }\end{aligned}$

31. Having your schedule center around diabetes

$\begin{aligned} & \text { Not Affected } \\ & \text { At all }\end{aligned}$
$\begin{aligned} & 1+3-4-5-6 \\ & \text { Affected }\end{aligned}$

32. Needing to rest often

$\begin{aligned} & \text { Not Affected } \\ & \text { At all }\end{aligned}$
$\begin{aligned} & 1 \\ & \text { Affected }\end{aligned}$

33. Problems in climbing steps

$\begin{aligned} & \text { Not Affected } \\ & \text { At all }\end{aligned}$
$\begin{aligned} & \text { Extremely } \\ & \text { Affected }\end{aligned}$

34. Having trouble caring for yourself (dressing, bathing, or using the toilet)

$\begin{aligned} & \text { Not Affected } \\ & \text { At all }\end{aligned}$
$\begin{aligned} & \text { Extremely } \\ & \text { Affected }\end{aligned}$

35. Restless sleep

$\begin{aligned} & \text { Not Affected } \\ & \text { At all }\end{aligned}$
$\begin{aligned} & \text { Affected } \\ & \text { Afremely }\end{aligned}$

36. Walking more slowly than others

$\begin{aligned} & \text { Not Affected } \\ & \text { At all }\end{aligned}$
$\begin{aligned} & \text { Extremely } \\ & \text { Affected }\end{aligned}$


37. Being labeled a diabetic

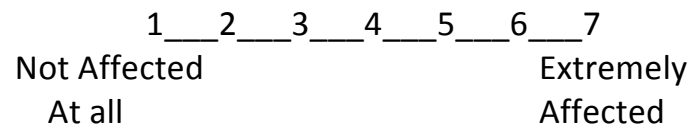

38. Having diabetes interfere with your family life

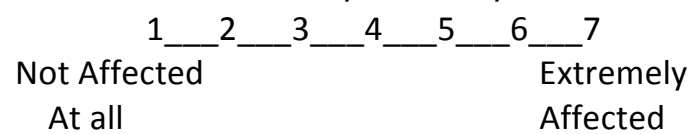

39. Diabetes in general

$\begin{aligned} & \text { Not Affected } \\ & \text { At all }\end{aligned}$
$\begin{aligned} & \text { Extremely } \\ & \text { Affected }\end{aligned}$

\section{OVERALL RATINGS}

1. Please place an " $X$ " on the line below that indicates your rating of your overall quality of life.

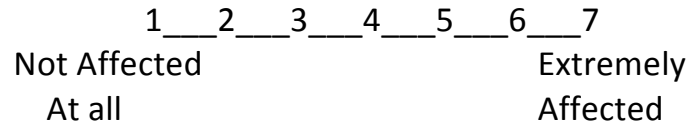

2. Please place an " $X$ " on the line below to show how severe you think your diabetes is.

$\begin{aligned} & \text { Not Affected } \\ & \text { At all }\end{aligned}$
$\begin{aligned} & \text { Extremely } \\ & \text { Affected }\end{aligned}$

